\section{Human cytomegalovirus vaccination: progress and perspectives of recombinant $\mathrm{gB}$}

\author{
Avneet Manghera' \& Gary R McLean ${ }^{* 1,2}$
}

\begin{abstract}
A vaccine for Human cytomegalovirus (HCMV) remains a high priority as complications following infection are observed in immunocompromised individuals and in congenitally infected neonates. Numerous preclinical and clinical studies have investigated vaccine strategies ranging from live attenuated preparations, nucleic acid-based approaches and recombinant delivery systems to subunit vaccines. These have defined the importance of both cell-mediated and humoral immunity to viral gB in the control of HCMV infection. This review will cover clinical trials investigating vaccine approaches that have incorporated $\mathrm{gB}$ and discuss the future perspectives of the recombinant $\mathrm{gB}$ subunit vaccine for HCMV.
\end{abstract}

First draft submitted: 7 March 2016; Accepted for publication: 18 April 2016;

Published online: 24 May 2016

\section{Background}

Human cytomegalovirus (HCMV) is a ubiquitous pathogen, known to infect all human populations worldwide [1]. It is an enveloped dsDNA virus that is the largest member of the Herpesviridae family that also includes important pathogens, such as HSV-1 and HSV-2, EBV and varicella zoster virus (VZV), all of which are widespread in human populations [2]. The HCMV genome is approximately $230 \mathrm{kbp}$ encoding 200-250 open reading frames, many of which facilitate immune evasion [3]. A recent study of the HCMV genome and translation products has suggested that it may be even more complex than anticipated with regulation of alternate transcripts allowing for numerous polypeptides to be expressed [4]. Transmission of HCMV predominantly occurs via body fluids, such as saliva, blood, urine and breast milk, leading to contact of the mucosal surfaces, primarily infecting epithelial and endothelial cells, followed by dissemination to numerous organs and tissues [5]. HCMV is, therefore, able to infect a wide range of cells including endothelial cells, epithelial cells, fibroblasts, smooth muscle cells, leukocytes and dendritic cells [5,6]. Similarly to other Herpesviridae family members, $\mathrm{HCMV}$ is capable of both lytic and latent infections [7], but primary infection and reactivation from latency are often asymptomatic in immunocompetent individuals [8]. HCMV infection and reactivation in both solid organ and hematopoietic stem cell transplant recipients, and fetal exposure in utero poses a major threat. Immunocompromised individuals, including AIDS patients $[9,10]$ and transplant patients [11,12], are at increased risk of both reactivation or reinfection, and primary HCMV infection has serious consequences for the developing fetus in pregnant women [8]. It is estimated that HCMV congenital infection occurs in $0.5-2 \%$ of all annual pregnancies [13], and approximately $10 \%$ of infants with congenital HCMV infection present with clinical manifestations at birth, such as hearing loss and neurological developmental defects [14]. Additionally, late-onset hearing disorders can occur with both symptomatic and asymptomatic congenital infection, which

'National Heart \& Lung Institute, Imperial College London, London, UK

${ }^{2}$ Cellular \& Molecular Immunology Research Centre, London Metropolitan University, London, UK

*Author for correspondence: g.mclean@imperial.ac.uk

\section{KEYWORDS}

- clinical trial • Human

cytomegalovirus

- recombinant $\mathrm{gB} \bullet$ vaccine 
outlines the importance of monitoring this population [15]. Treatments for HCMV in transplant recipients include the use of antiviral drugs [16], although viral resistance and toxicity restricts their use, and hyper immune globulins [17], which may also be effective in treating congenital infections [18]. Based on the widespread prevalence of HCMV, limited treatment options and the potential for significant morbidity, an effective vaccine preventing congenital infection and infection of the immunocompromised has been characterized as a level 1 priority by the Institute of Medicine [14].

\section{HCMV \& gB structure}

The HCMV envelope consists of several viral glycoproteins, including $\mathrm{gB}$, heterodimer $\mathrm{gH} / \mathrm{gL}$ and the $\mathrm{gM} / \mathrm{gN}$ complex [19] that play critical roles in viral entry and envelope fusion to cells [20]. These glycoproteins are also targets of the immune response to HCMV, eliciting neutralizing antibodies and cell-mediated immune responses, which suggests that they may serve as vaccine antigens. $\mathrm{gB}$ is probably the most well-studied viral glycoprotein and is highly conserved throughout the herpes virus family [21]. Together with $\mathrm{gH} / \mathrm{gL}$, gB mediates virus entry through membrane fusion and is known as the core fusion machinery common to all herpes viruses [22]. Studies have shown that $\mathrm{gH} / \mathrm{gL}$ along with $\mathrm{gB}$ plays an indispensable role in HCMV entry into fibroblasts and syncytium formation [23,24]. However, HCMV entry into other cell types, namely, epithelial cells and endothelial cells involves a complex of glycoproteins including $\mathrm{gH}, \mathrm{gL}$, UL128, UL130 and UL130A referred to as the $\mathrm{gH} / \mathrm{gL}$-pentamer complex (gH/gL-PC) [20,25]. In addition, $\mathrm{gH} / \mathrm{gL}-\mathrm{PC}$ is a prominent target for neutralizing antibodies that prevent infection of epithelial cells by HCMV [26-28]. Thus, the evidence points to the importance of both $\mathrm{gB}$ and $\mathrm{gH} / \mathrm{gL}-\mathrm{PC}$ for entry of HCMV and as key targets for antibodies.

The full-length gB polypeptide of 906 amino acids is cleaved by the human protease furin [29] into two disulfide-bonded subunits known as gp58 and gp116, and is expressed in the HCMV envelope via a hydrophobic transmembrane domain (Figure 1) [30]. The structure of the HCMV gB ectodomain has been recently solved independently by two groups [31,32] and is thought to adopt a post-fusion trimeric configuration in a similar fashion to that of HSV-1 and EBV gB [21,33-34]. However, the HCMV gB structure displays a unique domain arrangement.

The recombinant $\mathrm{gB}$ used for structural studies and adopted as a subunit vaccine was first described in 1996 by Norais [35]. This synthesized component contains the majority of the extracellular domain with the furin cleavage site mutated and the entire intracellular domain of Towne strain $\mathrm{gB}$ fused together with the intervening transmembrane domain deleted to facilitate secretion (Figure 1). The recombinant gene was expressed in Chinese hamster ovary cell cultures and secreted as a protein of 807 amino acids containing 19 putative $\mathrm{N}$-linked glycosylation sites. The structural studies required a truncated version of recombinant $\mathrm{gB}$ known as the ectodomain where the $\mathrm{N}$-terminal 78 residues, membrane proximal, transmembrane and cytoplasmic domains were removed to facilitate crystallization. Despite the lack of these regions, it is known to adopt the post fusion conformation spontaneously and provides information regarding antibody recognition, which has implications for vaccine design. In fact, these structures reflect the influence of $\mathrm{gB}$ glycosylation on antibody neutralization [31] and the interaction of a monoclonal antibody with a novel neutralizing epitope [32]. These recent discoveries are assisting with potential future modifications to $\mathrm{gB}$ that will improve its utility as a subunit vaccine.

\section{Immune response to $\mathrm{HCMV} \mathbf{g B}$}

As mentioned above, HCMV is able to infect a wide range of cells, such as endothelial cells, epithelial cells, fibroblasts, smooth muscle cells, leukocytes and dendritic cells [5,6], and this can influence the immune response generated. $\mathrm{HCMV}$ induces innate and adaptive immune responses that effectively resolve primary infection, however, it can still establish latency [36]. To complicate matters, HCMV is remarkable, in that it encodes numerous immune evasion molecules that target both innate and adaptive immune response mechanisms [36]. The innate immune response is triggered by detection and recognition of $\mathrm{HCMV} \mathrm{gB}$ and $\mathrm{gH}$ through Tolllike receptor 2 (TLR2) pathways [37], which leads to the initiation of the characteristic antiviral response inducing the production of type I interferons (IFN) and downstream expression of IFN-stimulated genes [38]. NK cells are thought to play an important role in innate control of $\mathrm{HCMV}$ infection as rare patients with NK cell deficiencies have increased severity of HCMV 


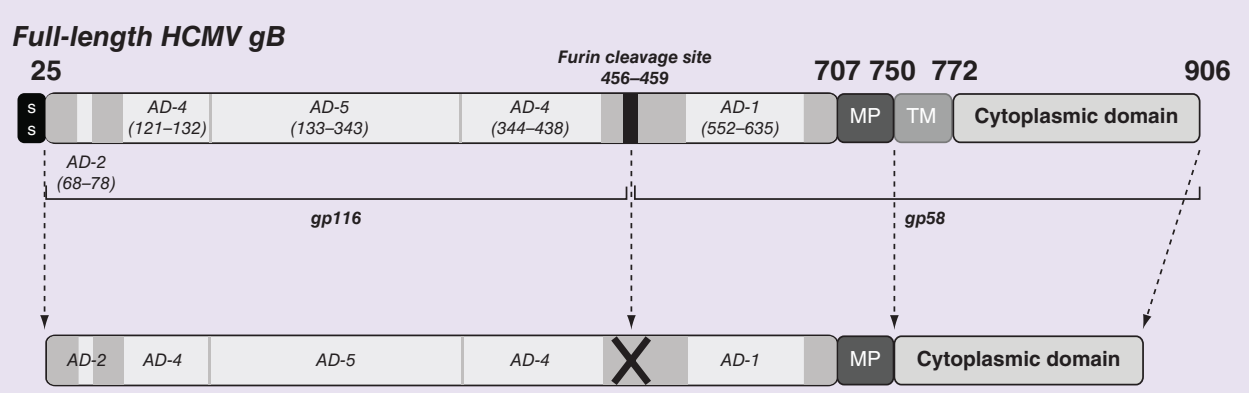

Recombinant HCMV gB (for subunit vaccine)

Figure 1. The full-length Human cytomegalovirus gB polypeptide and important domains (upper part). The extracellular domain consists of amino acids $25-750$ and contains several antigenic domains (AD-1, AD-2, AD-4, AD-5), the furin cleavage site and MP. A schematic of the synthesized recombinant $\mathrm{gB}$ that is used for $\mathrm{gB}$ subunit vaccine has a mutated furin cleavage site, and deleted $\mathrm{TM}$ domain is displayed below.

HCMV: Human cytomegalovirus; MP: Membrane proximal domain; SS: Signal sequence;

TM: Transmembrane domain.

infections [39] and the virus itself targets NK cell activation via encoding numerous mechanisms [36], although direct evidence is limited. Ultimately, the innate response plays an important role in modulating the adaptive arm of the response as it is the first step in recognition of the pathogen [40].

$\mathrm{T}$ cells and antibody-mediated immune responses help to protect against HCMV infection and disease. Neutralizing antibodies alone are not capable of controlling HCMV infection but do have the ability to protect against HCMVassociated diseases [41,42]. T-cell-mediated immunity is the hallmark response when fighting virus infections and human $\mathrm{T}$-cell responses to numerous HCMV glycoproteins have been identified in seropositive individuals $[43,44]$ with $\mathrm{gB}$ being a frequently found viral antigen for $\mathrm{CD} 4^{+}$ cells [45]. gB-specific cytotoxic CD8 ${ }^{+} \mathrm{T}$ cells and $\mathrm{gB}$-specific effector $\mathrm{CD} 4^{+} \mathrm{T}$ cells have been identified in HCMV-seropositive individuals [46], and $\mathrm{CD}^{+}$cytotoxic cells are capable of recognizing and destroying HCMV-infected cells [47]. $\mathrm{T}$ cells may, therefore, be critical for preventing dissemination of HCMV to other organs following initial infection of epithelial cells.

Antibodies to $\mathrm{HCMV} \mathrm{gB} \mathrm{in} \mathrm{human} \mathrm{sera} \mathrm{have}$ been demonstrated to numerous functional domains of $\mathrm{gB}$ and are thought to play a role in limiting viral spread [48]. Neutralizing antibody epitopes of HCMV gB have been very well characterized, and there are known to be five antigenic domains (AD), AD-1 to AD-5. Four of these domains have been mapped (AD-1, AD-2, $\mathrm{AD}-4$ and $\mathrm{AD}-5)$ to elicit human neutralizing antibodies [49]. AD-1 and AD-2 are the most well-characterized epitopes. AD-1 is a conformational epitope found on the C-terminal region of the $\mathrm{gB}$ polypeptide sequence at amino acids 552-635 (Figure 1), but is found at the tip of the $\mathrm{gB}$ spike in the folded structure [31]. AD-1 elicits a strong IgG response in all infected individuals, however, not all AD-1 binding antibodies have virus neutralizing capabilities [50]. AD-2 is a shorter linear epitope on the $\mathrm{N}$-terminus of the gB polypeptide (amino acids 68-78) (Figure 1) and, although not present in the solved gB structure, it is likely to be adjacent to the AD-1 epitope at the tip of the $\mathrm{gB}$ spike [51]. Antibodies generated to AD-2 are unique, in that they are potently neutralizing antibodies, but approximately only $50 \%$ of seropositive individuals generate antibodies to this site [52], which is thought to be due to proximity to the larger more immunogenic $\mathrm{AD}-1$ epitope in the $\mathrm{gB}$ structure, which results in antigenic competition during immune responses [51]. Furthermore, human B cells have been shown to perform limited VDJ recombination events that are required for antibodies that target $\mathrm{AD}-2$ [53], whereas there are numerous possibilities for generation of AD-1-specific antibodies. Interestingly, antibodies to AD-2 have been demonstrated to block placental infection of HCMV [54] and may, therefore, be the most critical site for antibodies to target to reduce vertical transmission. The AD-4 and AD-5 
regions have been identified and mapped much more recently by isolating human $\mathrm{B}$ cells with affinity for recombinant $\mathrm{gB}$ [49]. AD-4 is located in domain II of the $\mathrm{gB}$ structure [31], which is a discontinuous region covering amino acids 121-132 and 344-438 (Figure 1) and is well targeted by HCMV-infected individuals eliciting neutralizing antibodies [55]. AD-5 is located in domain I of the gB structure [31], which is a large region spanning amino acids 133-343 (Figure 1), and antibodies to this region are found in most cases of HCMV infection [49]. A smaller surfaceexposed region of AD-5 known as the YNND epitope is thought to be the exclusive target of neutralizing antibodies that bind AD-5 [56]. Thus, HCMV gB is a useful target for multiple aspects of the human immune response and has, therefore, been viewed as a promising candidate for development as an HCMV vaccine.

\section{Human trials of gB-containing HCMV vaccines}

Numerous live vaccines for HCMV have undergone clinical trials since the 1970s. Showing the best effects was live attenuated HCMV vaccine (Towne strain), which was reported to be immunogenic and decreased the severity of HCMVassociated disease in HCMV seronegative renal transplant patients receiving seropositive kidneys despite not preventing HCMV infection [57,58]. Importantly, it was noted that the vaccine did not undergo latency in these patients [59]. The advancement on this work looked at recombinant canarypox (ALVAC) as a vector for expressing HCMV gB (ALVAC-gB) [60]. ALVAC-gB was safe but only weakly immunogenic in seronegative subjects [61]. However, when administered prior to immunization with live Towne strain HCMV to seronegative adults, binding and neutralizing antibodies to $\mathrm{gB}$ were found to be induced sooner and titers were stronger and longer lived than those receiving live Towne strain alone [61]. It was, therefore, suggested that this approach of priming followed by live vaccination may help to boost a protective antibody response. A similar priming effect has been shown with an HCMV trivalent DNA vaccine (VCL-CT02) encoding sequences of pp65, IE 2 and $\mathrm{gB}$. Administration of VCL-CT02 prior to live Towne strain resulted in the boosting of memory HCMV-specific antibody responses to $\mathrm{gB}$ and $\mathrm{pp} 65$-specific $\mathrm{CD}^{+} \mathrm{T}$-cell responses [62]. Further trials of a DNA vaccine encoding HCMV gB and pp65 were performed in hematopoietic stem cell transplant patients. Results showed that the vaccine was well tolerated and reduced the occurrence and recurrence of HCMV viremia [63]. A brief summary of these trials is shown in Table 1.

\section{Human trials of subunit $\mathrm{gB}$ vaccine}

Recombinant HCMV gB was first used in a Phase I trial in conjunction with adjuvant MF59 [64]. Here, a double-blind, randomized, placebo-controlled was performed with healthy adult HCMV-seronegative volunteers receiving intramuscular (im.) one of three doses (5, 30 or $100 \mu \mathrm{g}$; ten subjects/group) and comparing with $100 \mu \mathrm{g}$ of HCMV gB with alum (ten subjects) or placebo (six subjects). Immunizations were given at enrolment, 1 and 6 months later. A fourth dose of vaccine was given 12 months after the first immunization to subjects who consented to participate in an extension with 12 months of follow-up after the fourth immunization. The vaccine was safe and generated $\mathrm{gB}$ specific neutralizing antibodies at levels greater than seropositive control subjects following three

\begin{tabular}{|c|c|c|c|c|}
\hline Study (year) & HCMV vaccine & Patient group(s) & Key findings & Ref. \\
\hline $\begin{array}{l}\text { Sachs et al. (1984), Plotkin } \\
\text { et al. (1985), Plotkin et al. } \\
\text { (1991) }\end{array}$ & Live Towne strain & Renal transplant recipients & $\begin{array}{l}\text { Decreased severity of HCMV disease in } \\
\text { seronegative patients receiving seropositive } \\
\text { transplants }\end{array}$ & [57-59] \\
\hline $\begin{array}{l}\text { Gonczol et al (1995), Adler } \\
\text { et al. (1999) }\end{array}$ & $\begin{array}{l}\text { ALVAC-gB prime and live } \\
\text { Towne }\end{array}$ & $\begin{array}{l}\text { Healthy } \\
\text { HCMV-seronegative adults }\end{array}$ & $\begin{array}{l}\text { Weakly immunogenic but in combination } \\
\text { with live Towne induces strong and long-lived } \\
\text { neutralizing antibody responses }\end{array}$ & {$[60,61]$} \\
\hline Jacobson et al. (2009) & $\begin{array}{l}\text { Trivalent DNA } \\
\text { (gB/pp65/IE1) prime and } \\
\text { live Towne }\end{array}$ & $\begin{array}{l}\text { Healthy } \\
\text { HCMV-seronegative adults }\end{array}$ & $\begin{array}{l}\text { Increased cell-mediated immune responses } \\
\text { and gB-specific antibody responses }\end{array}$ & [62] \\
\hline $\begin{array}{l}\text { Kharfan-Dabaja et al. } \\
(2012)\end{array}$ & Bivalent DNA (gB/pp65) & $\begin{array}{l}\text { Hemopoietic stem cell } \\
\text { transplant recipients }\end{array}$ & Reduced reactivation of $\mathrm{HCMV}$ viremia & [63] \\
\hline
\end{tabular}


injections and even more so in the group receiving a fourth dose. The two lower doses of $\mathrm{gB}$ were found to be the most effective and MF59 adjuvant induced stronger antibody responses than alum.

A parallel Phase I trial of HCMV gB adjuvanted with MF59 was performed to evaluate safety and immunogenicity of low doses of 5 and $30 \mu \mathrm{g}$ in $95 \mathrm{HCMV}$-seronegative individuals [65]. Each dose was administered im. in one of three immunization schedules: 0,1 and 2 months; 0 , 1 and 4 months; or 0,1 and 6 months. Despite the significantly higher incidences of pain, warmth and myalgia at the injection site of the $30-\mu \mathrm{g}$ dose vaccine, overall the $\mathrm{gB}$ vaccine was well tolerated at both doses. Biochemical analysis of the blood showed no significant changes in complete blood counts or liver/renal function. Interestingly, there was no significant difference in anti-gB antibody titers between the 5-and $30-\mu \mathrm{g}$ dose groups after the final immunization. However, 6 months post final immunization, there was a significantly higher antibody titer in the 0-, 1- and 6-month schedule in comparison with the others, emphasizing the importance of spacing out the doses to allow for a maximal longlived immune response. However, neutralizing antibody titers, although significantly higher in the 0 -, 1 - and 6-month group at 2 weeks postthird immunization, was lost after 12 months. Thus, a result that was common to both of these Phase I subunit $\mathrm{gB}$ vaccine trials was that the antibody levels generated were not long lasting - an issue that remains unresolved but that may point to a requirement for continued antigenic stimulation of the immune response as is seen with natural HCMV infection.

A Phase I clinical trial of gB/MF59 was performed in healthy young children (age range: 12-35 months) to further evaluate safety and immunogenicity [66]. Fifteen children received a 20- $\mu \mathrm{g}$ dose of gB/MF59 im. at 0, 1 and 6 months and adverse reactions were monitored along with $\mathrm{gB}$-specific antibodies and HCMV neutralizing antibodies. It was concluded that the vaccine was well tolerated and highly immunogenic, with gB-specific and neutralizing antibodies reaching higher levels than seen in naturally infected adults and in adults given the gB/MF59 vaccine.

Further progress has been made with the MF59 adjuvanted gB subunit vaccine. Phase II trials have been performed where it was administered to women of child-bearing age [67].
This study published in 2009 was a placebocontrolled, randomized, double-blind trial, where $\mathrm{gB} / \mathrm{MF} 59$ vaccine $(\mathrm{n}=234)$ or placebo $(\mathrm{n}=230)$ were given at 0,1 and 6 months to HCMV-seronegative women within 1 year after having given birth. The primary end point was the time until the detection of HCMV infection as determined by the presence of antibody to HCMV proteins other than $\mathrm{gB}$. After 1 year of follow-up, there were 18 confirmed HCMV infections in the vaccine group compared with 31 in the placebo group. Vaccine efficacy was calculated at $50 \%$ on the basis of infection rates per 100 person years. Just one congenital infection among infants of the subjects occurred in the vaccine group, whereas three infections occurred in the placebo group. While these results were encouraging, vaccine efficacy was relatively low and pointed to limited role of neutralizing antibody to $\mathrm{gB}$ alone as a useful correlate of protection.

$\mathrm{gB} / \mathrm{MF} 59$ has also been administered to transplant patients [68]. Here a randomized, placebo-controlled Phase II trial was performed in adults awaiting kidney or liver transplantation. Both HCMV-seronegative and -seropositive patients were randomly assigned to receive either $\mathrm{gB} / \mathrm{MF} 59$ vaccine or placebo, each given at baseline, 1 month and 6 months later. End points were receipt of a transplant, HCMV viremia, immunogenicity and safety. Levels of gB-specific antibody were increased in both seronegative and seropositive patients in vaccine recipients as compared with placebo. The patients that developed viremia after transplantation displayed a shorter duration that correlated with higher levels of gB-specific antibodies. In the seronegative patients receiving a transplant from a seropositive donor, the vaccine reduced the length of viremia and the amount of time undergoing ganciclovir treatment. These results are significant since it is known that transplant-associated immune suppression via reduced cell-mediated immunity leads to HCMV disease, however, vaccine induction of $\mathrm{gB}$-specific antibodies can, therefore, assist and again point to being a useful correlate of protection.

The most recent study of $\mathrm{gB} / \mathrm{MF} 59$ was conducted in healthy seronegative adolescent girls [69]. This Phase II study was designed to determine safety and efficacy with an end point based on evidence of HCMV infection. Subjects were dosed with gB/MF59 or placebo at 0,1 and 6 months. The vaccine was safe, generated gB 
antibody in all vaccine recipients, and efficacy was determined to be $43 \%$, which is lower than conventional levels of significance but in line with prior investigations with the same formulation [67].

Thus three independent Phase II trials of $\mathrm{gB} / \mathrm{MF} 59$ have indicated that antibody to $\mathrm{gB}$ is a possible correlate of protection for primary HCMV infection. Studies have yet to establish the role of $\mathrm{gB}$ vaccination (and, therefore, antibody protection) in HCMV reactivation. However, one clinical study has highlighted that $\mathrm{gB}$ vaccination can generate a limited cellmediated immune response and is suggestive of an important role of $\mathrm{CD}^{+}{ }^{+} \mathrm{T}$ cells in vertical HCMV transmission and potentially reinfection [70]. Interestingly, gB/MF59 boosted both the antibody-mediated and $\mathrm{CD} 4{ }^{+} \mathrm{T}$-cells responses to $\mathrm{gB}$ in chronically $\mathrm{HCMV}$-infected women. In particular, these $\mathrm{CD} 4^{+} \mathrm{T}$ cells were found to release IFN- $\gamma$, indicating a type-I response that is known to activate $\mathrm{CD} 8^{+} \mathrm{T}$ cells. In addition, the $\mathrm{CD}^{+} \mathrm{T}$ cells had increased expression of the CD40 ligand (CD40L), a ligand that is a marker of recently activated $\mathrm{T}$ cells and also associated with T-cell-dependent antibody responses. All boosted responses were directly attributed to the $\mathrm{gB}$ vaccine as no boosting of responses to alternate HCMV proteins was observed [70]. Taken together, these findings demonstrate that $\mathrm{gB} / \mathrm{MF} 59$ induces cellmediated immunity that helps boost pre-existing cell-mediated and antibody responses to $\mathrm{gB}$. The application of $\mathrm{gB} / \mathrm{MF} 59$, therefore, warrants further trial in HCMV-seropositive recipients with reactivation as the primary end point. A summary of the $\mathrm{gB} / \mathrm{MF} 59$ trials outlined above is shown in Table 2.

The future of HCMV gB subunit vaccine

Several clinical studies have outlined the importance of both cell-mediated and humoral immunity to $\mathrm{gB}$ in the control HCMV infection of both healthy individuals and also immunocompromised hosts where the disease burden is most significant [41-43,45-47]. Maternal IgG is also critical in protection of the unborn fetus from congenital HCMV infection $[18,41]$. Numerous vaccine approaches such as live virus strains and recombinant delivery vectors have been attempted since the 1970s (Table 1), and while many have displayed reasonable efficacy, a licensed HCMV vaccine that will protect the most at-risk groups still does not exist. The difficultly appears to arise through the complex immunity required for complete protection to HCMV and the lack of knowledge of exactly what constitutes immune correlates of protection [36]. Even the immunity acquired via natural HCMV exposure, which is sufficient for initial viral clearance and recovery from infection in most individuals, does not fully protect from the high probability of reactivation due to the latent life cycle of the virus and the numerous immune evasion strategies the virus can adopt [36]. It has, therefore, been difficult to replicate long-lived protective immunity to HCMV with the vaccine approaches employed to date.

A new generation of vaccine candidates has been explored, one of which is the subunit $\mathrm{gB}$ immunogen that is adjuvanted with MF59. This approach has offered hope by displaying clinical efficacy through the generation of relatively robust neutralizing antibody titers and possibly through the induction of cell-mediated immunity $[67,68]$. Importantly, the $\mathrm{gB} / \mathrm{MF} 59$ is safe in children [66] and adults [64,65], as well as being immunogenic, but is clearly not the ideal HCMV vaccine yet - improvements are required.

It still needs to be determined if $\mathrm{gB} / \mathrm{MF} 59$ induces the full spectrum of $\mathrm{gB}$ neutralizing antibodies observed following natural exposure. Neutralizing antibodies are induced with $\mathrm{gB} / \mathrm{MF} 59$ in seronegative recipients [64-68] and boosted in seropositive recipients [68]. While it is likely that $\mathrm{gB} / \mathrm{MF} 59$ induces antibodies to the major neutralizing epitopes AD-1, AD-2, AD-4 and AD-5, no study has yet evaluated this completely. Responses to AD-2 following vaccination with live Towne strain with and without ALVAC-gB priming or gB/MF59 displayed similarities to natural exposure, that is, only a fraction of recipients produced AD-2-specific antibodies [71]. This limited response to AD-2 is probably due to AD-1 antibodies out-competing the response to this epitope as described previously [51] and has suggested that modifications to recombinant $\mathrm{gB}$ or the vaccine regimen itself may improve responses to AD-2 and, therefore, improve vaccine efficacy [51,72]. Antibodies binding AD-1, AD-4 and AD-5 have not been investigated in $\mathrm{gB} / \mathrm{MF} 59$ recipients. However, further studies mapping the neutralizing antibody responses to $\mathrm{gB} / \mathrm{MF} 59$ will be forthcoming and will indicate improvements that could be made to the existing gB/MF59 strategy. They may even identify novel neutralizing epitopes that have not been found in prior studies. 
The limited longevity of the immune responses generated by gB/MF59 vaccination also needs addressing. Studies in seronegative recipients have indicated that protective responses are not long lived [65], and a similar loss of boosted responses in seropositive recipients has been noted [68]. This is observed despite three separate administrations of vaccine over a 6-month regimen and in one study a fourth dose after 12 months and suggests that there is a limited T-helper response generated to the vaccine. Perhaps it is worth investigating a protracted regimen over a longer period to improve longevity. Interestingly, toddlers that received gB/MF59 displayed higher titer antibody responses than adults [66], suggesting that a longer vaccination regimen in these individuals and natural HCMV exposure may promote long-lived immunity into adulthood. Alternatively, improved adjuvants could be applied. There are currently four adjuvants licensed for use in humans, oil-inwater emulsions AS03 and MF59, alum and an alum monophosphoryl lipid A combination (AS04) [73]. These adjuvants may not provoke the desired immune responses in recipients and work is underway to develop tuneable adjuvant formulations [73].

Cellular immune responses to HCMV are critical for complete protective immunity to HCMV and these responses are clearly not optimally delivered by a recombinant subunit vaccine approach. Nevertheless, gB-specific $\mathrm{CD}^{+}{ }^{+}$responses following gB/MF59 have been observed in seropositive recipients [70], but this has not been determined in seronegative recipients. It is likely that $\mathrm{gB}$ alone in the seronegative recipients does not promote a broad enough cellular immune response. Therefore, it may be desirable to increase the valency of the subunit HCMV vaccine candidates to include other targets $(\mathrm{gH} / \mathrm{gL}$ and $\mathrm{gM} / \mathrm{gN})$ in combination with $\mathrm{gB}$. This approach would deliver more broad antibody coverage but may not deliver the required cellular responses adequately so a prime and boost regimen could be favored. Thus, another approach might be to increase vaccine valency by using $\mathrm{gB}$ in combination with dominant T-cell antigens, such as IE1 and pp65 [74-76]. A possible avenue for generation of suitable immunity might be to use DNAbased vaccines, which encode key antigens that can prime both $\mathrm{B}$ and $\mathrm{T}$ cells prior to $\mathrm{gB}$ [77]. In Phase II trials, this priming approach in

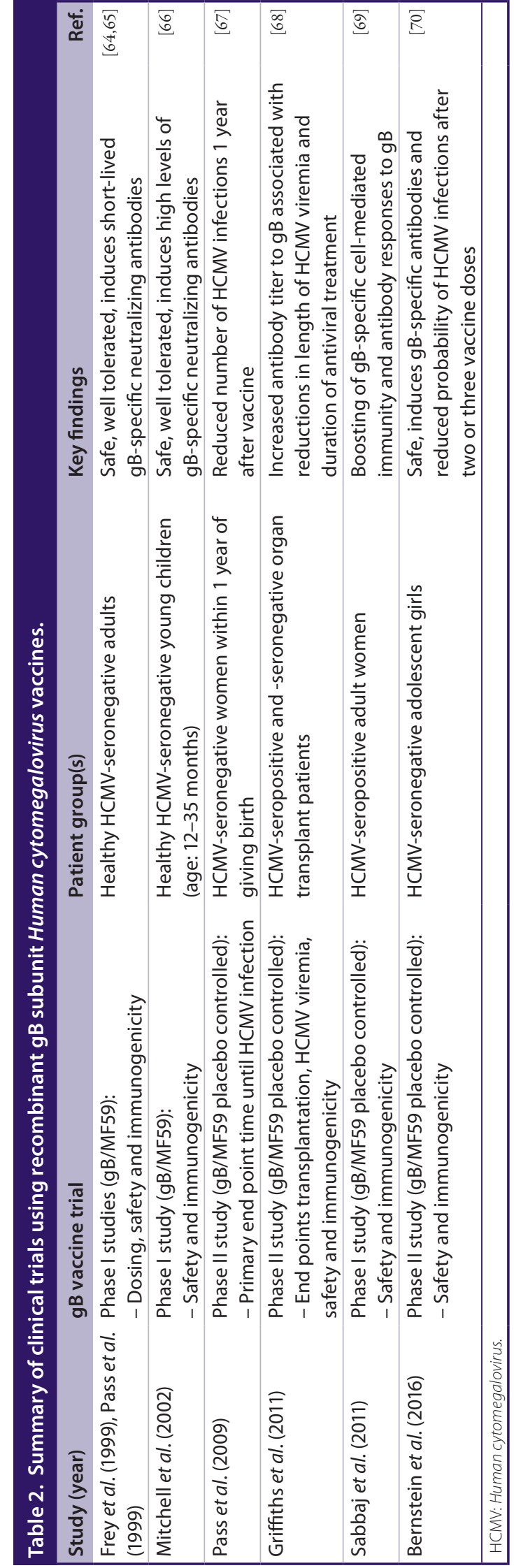


combination with live boosting was shown to reduce $\mathrm{HCMV}$ viremia and also to increase the production of memory HCMV-specific antibodies $[62,63]$. To our knowledge, the DNA priming approach followed by $\mathrm{gB} / \mathrm{MF} 59$ boosting has not been attempted.

Overall, the development and relative success of the recently trialed $\mathrm{gB} / \mathrm{MF} 59$ subunit vaccine is encouraging and offers a new outlook to what was previously known about immunity to $\mathrm{gB}$ and, therefore, protection against HCMV. Nevertheless, potential improvements such as immunogen redesign to induce broader neutralizing antibody responses and regimen modifications to improve response longevity and cell-mediated responses may induce a more efficacious vaccine for the often serious consequences attributed to HCMV infection. The possibility of a multivalent subunit immunogen approach that includes $\mathrm{gB}$ and other important HCMV targets to broaden protective immune responses should also be investigated. In this regard, the importance of the $\mathrm{gH} / \mathrm{gL}-\mathrm{PC}$ cannot be underestimated and is coincidentally under development as a potential HCMV vaccine [78].

\section{EXECUTIVE SUMMARY}

\section{Background}

- Human cytomegalovirus (HCMV) is a ubiquitous human pathogen of the Herpesviridae family.

- It is a large complex DNA virus transmitted by body fluids.

- HCMV infects a wide range of cells and has both lytic and latent life cycles.

- It is a critical pathogen for the immunocompromised, transplant recipients and congenitally infected babies.

- There are few effective treatments and no licensed vaccine is available.

\section{HCMV \& gB structure}

- The HCMV envelope contains numerous glycoproteins that are conserved within the herpes virus family.

- $\mathrm{gB}$ is the most-studied HCMV glycoprotein and is critical for viral entry.

- The gB crystal structure has been recently solved.

- Recombinant gB has been synthesized and used as a subunit vaccine.

\section{Immune response to $\mathrm{HCMV} \mathrm{gB}$}

- HCMV induces innate and adaptive immune responses that can resolve primary infection.

- Cytotoxic and helper T-cell responses to gB have been demonstrated.

- Neutralizing antibody responses to four antigenic determinants ( $A D-1, A D-2, A D-4, A D-5)$ of $g B$ have been extensively studied.

\section{Human trials of gB-containing HCMV vaccines}

- Live attenuated vaccines have been tested and display varying efficacy.

- Recombinant delivery systems of HCMV gB have been trialed in humans.

- Trivalent DNA vaccines have also been trialed in humans.

- Prime-boost regimens show the best efficacy.

\section{Human trials of subunit $\mathrm{gB}$ vaccine}

- Recombinant gB adjuvanted with MF59 has undergone several clinical trials.

- gB/MF59 is safe and immunogenic but displays limited efficacy in Phase II trials.

- Antibody responses to gB appear to be a useful correlate of protection.

\section{The future of $\mathrm{HCMV} \mathrm{gB}$ subunit vaccine}

- Numerous vaccine approaches have been trialed but a licensed HCMV vaccine does not yet exist.

- The gB subunit vaccine is promising but modifications and improvements to the immunogen, formulation and regimen are required to boost efficacy. 


\section{Conclusion \& future perspective}

The use of $\mathrm{gB}$ as a subunit vaccine for HCMV has shown encouraging results but will more than likely not provide the immunity required for complete protection. Modifications to the immunogen itself, additional immunogens in the formulation, improved adjuvants and alterations to the administration regimen are the key changes that could make improvements to the $\mathrm{gB}$ vaccine, ultimately making it successful in future clinical trials.

\section{Financial \& competing interests disclosure}

The authors have no relevant affiliations or financial involvement with any organization or entity with a financial interest in or financial conflict with the subject matter or materials discussed in the manuscript. This includes employment, consultancies, honoraria, stock ownership or options, expert testimony, grants or patents received or pending, or royalties.

No writing assistance was utilized in the production of this manuscript.

\section{References}

Papers of special note have been highlighted as:

- of interest; $\bullet \bullet$ of considerable interest

1 Cannon MJ, Schmid DS, Hyde TB. Review of Cytomegalovirus seroprevalence and demographic characteristics associated with infection. Rev. Med. Virol. 20(4), 202-213 (2010).

2 Grinde B. Herpesviruses: latency and reactivation - viral strategies and host response. J. Oral Microbiol. 5, 10.3402/jom. v5i0.22766 (2013) (Online).

3 Britt WJ, Boppana S. Human cytomegalovirus virion proteins. Hum. Immunol. 65(5), 395-402 (2004).

4 Stern-Ginossar N, Weisburd B, Michalski A et al. Decoding Human cytomegalovirus. Science 338(6110), 1088-1093 (2012).

5 Sinzger C, Digel M, Jahn G. Cytomegalovirus cell tropism. Curr. Top. Microbiol. Immunol. 325, 63-83 (2008).

6 Scrivano L, Sinzger C, Nitschko H, Koszinowski UH, Adler B. HCMV spread and cell tropism are determined by distinct virus populations. PLoS Pathog. 7(1), e1001256 (2011).

7 Dupont L, Reeves MB. Cytomegalovirus latency and reactivation: recent insights into an age old problem. Rev. Med. Virol. 26(2), 75-89 (2016)

8 Nogalski MT, Collins-Mcmillen D, Yurochko AD. Overview of Human cytomegalovirus pathogenesis. Methods Mol. Biol. 1119, 15-28 (2014).

9 Gerna G, Parea M, Percivalle E et al. Human cytomegalovirus viraemia in HIV-1seropositive patients at various clinical stages of infection. AIDS 4(10), 1027-1031 (1990).

10 Wolf DG, Spector SA. Diagnosis of Human cytomegalovirus central nervous system disease in AIDS patients by DNA amplification from cerebrospinal fluid. J. Infect. Dis. 166(6), 1412-1415 (1992).
11 Kotton CN. Management of Cytomegalovirus infection in solid organ transplantation. Nat. Rev. Nephrol. 6(12), 711-721 (2010).

12 Opelz G, Dohler B, Ruhenstroth A. Cytomegalovirus prophylaxis and graft outcome in solid organ transplantation: a collaborative transplant study report. $\mathrm{Am}$. J. Transplant 4(6), 928-936 (2004).

13 Kovacs A, Schluchter M, Easley K et al. Cytomegalovirus infection and HIV-1 disease progression in infants born to HIV-1-infected women. Pediatric Pulmonary and Cardiovascular Complications of Vertically Transmitted HIV Infection Study Group. N. Engl. J. Med. 341(2), 77-84 (1999).

14 Arvin AM, Fast P, Myers M, Plotkin S, Rabinovich R. Vaccine development to prevent Cytomegalovirus disease: report from the National Vaccine Advisory Committee. Clin. Infect. Dis. 39(2), 233-239 (2004).

15 Dahle AJ, Fowler KB, Wright JD, Boppana SB, Britt WJ, Pass RF. Longitudinal investigation of hearing disorders in children with congenital Cytomegalovirus. J. Am. Acad. Audiol. 11(5), 283-290 (2000).

16 Lischka P, Zimmermann H. Antiviral strategies to combat Cytomegalovirus infections in transplant recipients. Curr. Opin. Pharmacol. 8(5), 541-548 (2008).

17 Bonaros N, Mayer B, Schachner T, Laufer G, Kocher A. CMV-hyperimmune globulin for preventing Cytomegalovirus infection and disease in solid organ transplant recipients: a meta-analysis. Clin. Transplant. 22(1), 89-97 (2008).

18 Nigro G, Adler SP, La Torre R, Best AM. Passive immunization during pregnancy for congenital Cytomegalovirus infection. N. Engl. J. Med. 353(13), 1350-1362 (2005).

19 Britt WJ, Mach M. Human cytomegalovirus glycoproteins. Intervirology 39(5-6), 401-412 (1996).
20 Vanarsdall AL, Johnson DC. Human cytomegalovirus entry into cells. Curr. Opin. Virol. 2(1), 37-42 (2012).

21 Sharma S, Wisner TW, Johnson DC, Heldwein EE. HCMV gB shares structural and functional properties with $\mathrm{gB}$ proteins from other herpesviruses. Virology 435(2), 239-249 (2013).

22 Heldwein EE, Krummenacher C. Entry of herpesviruses into mammalian cells. Cell. Mol. Life Sci. 65(11), 1653-1668 (2008).

23 Kinzler ER, Compton T. Characterization of Human cytomegalovirus glycoprotein-induced cell-cell fusion. J. Virol. 79(12), 7827-7837 (2005).

24 Tugizov S, Navarro D, Paz P, Wang Y, Qadri I, Pereira L. Function of Human cytomegalovirus glycoprotein B: syncytium formation in cells constitutively expressing gB is blocked by virus-neutralizing antibodies. Virology 201(2), 263-276 (1994).

25 Ryckman BJ, Rainish BL, Chase MC et al. Characterization of the Human cytomegalovirus $\mathrm{gH} / \mathrm{gL} / \mathrm{UL} 128-131$ complex that mediates entry into epithelial and endothelial cells. J. Virol. 82(1), 60-70 (2008).

26 Gerna G, Sarasini A, Patrone M et al. Human cytomegalovirus serum neutralizing antibodies block virus infection of endothelial/epithelial cells, but not fibroblasts, early during primary infection. J. Gen. Virol. 89(Pt 4), 853-865 (2008).

27 Macagno A, Bernasconi NL, Vanzetta F et al. Isolation of human monoclonal antibodies that potently neutralize Human cytomegalovirus infection by targeting different epitopes on the gH/gL/UL128131 A complex. J. Virol. 84(2), 1005-1013 (2010).

28 Genini E, Percivalle E, Sarasini A, Revello MG, Baldanti F, Gerna G. Serum antibody response to the $\mathrm{gH} / \mathrm{gL} / \mathrm{pUL} 128-131$ five-protein complex of Human cytomegalovirus (HCMV) in primary and reactivated HCMV infections. J. Clin. Virol. 52(2), 113-118 (2011). 
29 Vey M, Schafer W, Reis B et al. Proteolytic processing of Human cytomegalovirus glycoprotein B (gpUL55) is mediated by the human endoprotease furin. Virology 206(1), 746-749 (1995).

30 Britt WJ, Auger D. Synthesis and processing of the envelope gp55-116 complex of Human cytomegalovirus. J. Virol. 58(1), 185-191 (1986).

31 Burke HG, Heldwein EE. Crystal structure of the Human cytomegalovirus glycoprotein B. PLoS Pathog. 11(10), e1005227 (2015).

-. Solves the crystal structure of gB, which will be an important guide for further vaccine design.

32 Chandramouli S, Ciferri C, Nikitin PA et al. Structure of HCMV glycoprotein B in the postfusion conformation bound to a neutralizing human antibody. Nat. Commun. 6, 8176 (2015).

33 Heldwein EE, Lou H, Bender FC, Cohen GH, Eisenberg RJ, Harrison SC. Crystal structure of glycoprotein B from herpes simplex virus 1. Science 313(5784), 217-220 (2006).

34 Backovic M, Longnecker R, Jardetzky TS. Structure of a trimeric variant of the Epstein-Barr virus glycoprotein B. Proc. Natl Acad. Sci. USA 106(8), 2880-2885 (2009).

35 Norais N, Hall JA, Gross L et al. Evidence for a phosphorylation site in Cytomegalovirus glycoprotein gB. J. Virol. 70(8), 5716-5719 (1996).

36 Jackson SE, Mason GM, Wills MR. Human cytomegalovirus immunity and immune evasion. Virus Res. 157(2), 151-160 (2011).

37 Boehme KW, Guerrero M, Compton T. Human cytomegalovirus envelope glycoproteins $\mathrm{B}$ and $\mathrm{H}$ are necessary for TLR2 activation in permissive cells. J. Immunol. 177(10), 7094-7102 (2006).

38 Boehme KW, Singh J, Perry ST, Compton T. Human cytomegalovirus elicits a coordinated cellular antiviral response via envelope glycoprotein B. J. Virol. 78(3), 1202-1211 (2004).

39 Biron CA, Byron KS, Sullivan JL. Severe herpesvirus infections in an adolescent without natural killer cells. N. Engl. J. Med. 320 (26), 1731-1735 (1989).

40 Isaacson MK, Juckem LK, Compton T. Virus entry and innate immune activation. Curr. Top. Microbiol. Immunol. 325, 85-100 (2008).

41 Fowler KB, Stagno S, Pass RF, Britt WJ, Boll TJ, Alford CA. The outcome of congenital
Cytomegalovirus infection in relation to maternal antibody status. N. Engl. J. Med. 326(10), 663-667 (1992).

42 Alberola J, Tamarit A, Cardenoso L, Estelles F, Igual R, Navarro D. Longitudinal analysis of Human cytomegalovirus glycoprotein B $(\mathrm{gB})$-specific and neutralizing antibodies in AIDS patients either with or without Cytomegalovirus end-organ disease. J. Med. Virol. 64(1), 35-41 (2001).

43 Beninga J, Kropff B, Mach M. Comparative analysis of fourteen individual Human cytomegalovirus proteins for helper T cell response. J. Gen. Virol. 76(Pt 1), 153-160 (1995).

44 Sylwester AW, Mitchell BL, Edgar JB et al. Broadly targeted Human cytomegalovirusspecific $\mathrm{CD}^{+}{ }^{+}$and $\mathrm{CD} 8{ }^{+} \mathrm{T}$ cells dominate the memory compartments of exposed subjects. J. Exp. Med. 202(5), 673-685 (2005).

$45 \mathrm{He} \mathrm{H}$, Rinaldo CR Jr, Morel PA. T cell proliferative responses to five Human cytomegalovirus proteins in healthy seropositive individuals: implications for vaccine development. J. Gen. Virol. 76(Pt 7), 1603-1610 (1995).

46 Hopkins JI, Fiander AN, Evans AS, Delchambre M, Gheysen D, Borysiewicz LK. Cytotoxic T cell immunity to Human cytomegalovirus glycoprotein B. J. Med. Virol. 49(2), 124-131 (1996).

47 Hegde NR, Dunn C, Lewinsohn DM, Jarvis MA, Nelson JA, Johnson DC. Endogenous Human cytomegalovirus $\mathrm{gB}$ is presented efficiently by MHC class II molecules to CD4 ${ }^{+}$CTL. J. Exp. Med. 202(8), 1109-1119 (2005).

48 Navarro D, Lennette E, Tugizov S, Pereira L. Humoral immune response to functional regions of Human cytomegalovirus glycoprotein B. J. Med. Virol. 52(4), 451-459 (1997).

49 Potzsch S, Spindler N, Wiegers AK et al. B cell repertoire analysis identifies new antigenic domains on glycoprotein B of Human cytomegalovirus which are target of neutralizing antibodies. PLoS Pathog. 7(8), e1002172 (2011)

50 Speckner A, Glykofrydes D, Ohlin M, Mach M. Antigenic domain 1 of Human cytomegalovirus glycoprotein B induces a multitude of different antibodies which, when combined, results in incomplete virus neutralization. J. Gen. Virol. 80 (Pt 8), 2183-2191 (1999).

51 Schrader JW, Mclean GR. Location, location, timing: analysis of Cytomegalovirus epitopes for neutralizing antibodies. Immunol. Lett. 112(1), 58-60 (2007).
52 Lantto J, Fletcher JM, Ohlin M. Binding characteristics determine the neutralizing potential of antibody fragments specific for antigenic domain 2 on glycoprotein B of Human cytomegalovirus. Virology 305(1), 201-209 (2003).

53 Mclean GR, Olsen OA, Watt IN et al. Recognition of Human cytomegalovirus by human primary immunoglobulins identifies an innate foundation to an adaptive immune response. J. Immunol. 174(8), 4768-4778 (2005).

54 Zydek M, Petitt M, Fang-Hoover J et al. HCMV infection of human trophoblast progenitor cells of the placenta is neutralized by a human monoclonal antibody to glycoprotein $\mathrm{B}$ and not by antibodies to the pentamer complex. Viruses 6(3), 1346-1364 (2014).

- Demonstrates that transplacental transfer of Human cytomegalovirus (HCMV) may be limited by antibodies to $\mathrm{gB}$.

55 Spindler N, Rucker P, Potzsch S et al. Characterization of a discontinuous neutralizing epitope on glycoprotein B of Human cytomegalovirus. J. Virol. 87(16), 8927-8939 (2013).

56 Wiegers AK, Sticht H, Winkler TH, Britt WJ, Mach M. Identification of a neutralizing epitope within antigenic domain 5 of glycoprotein B of Human cytomegalovirus. J. Virol. 89(1), 361-372 (2015).

57 Sachs GW, Simmons RL, Balfour HH Jr. Cytomegalovirus vaccine: persistence of humoral immunity following immunization of renal transplant candidates. Vaccine 2(3), 215-218 (1984).

58 Plotkin SA, Starr SE, Friedman HM et al. Effect of Towne live virus vaccine on Cytomegalovirus disease after renal transplant. A controlled trial. Ann. Intern. Med. 114(7), 525-531 (1991).

59 Plotkin SA, Huang ES. Cytomegalovirus vaccine virus (Towne strain) does not induce latency. J. Infect. Dis. 152(2), 395-397 (1985).

60 Gonczol E, Berensci K, Pincus S et al. Preclinical evaluation of an ALVAC (canarypox) - Human cytomegalovirus glycoprotein B vaccine candidate. Vaccine 13(12), 1080-1085 (1995).

61 Adler SP, Plotkin SA, Gonczol E et al. A canarypox vector expressing Cytomegalovirus (CMV) glycoprotein B primes for antibody responses to a live attenuated CMV vaccine (Towne). J. Infect. Dis. 180(3), 843-846 (1999).

62 Jacobson MA, Adler SP, Sinclair E et al. A CMV DNA vaccine primes for memory 
immune responses to live-attenuated CMV (Towne strain). Vaccine 27(10), 1540-1548 (2009).

63 Kharfan-Dabaja MA, Boeckh M, Wilck MB et al. A novel therapeutic Cytomegalovirus DNA vaccine in allogeneic haemopoietic stem-cell transplantation: a randomised, double-blind, placebo-controlled, Phase 2 trial. Lancet 12(4), 290-299 (2012).

64 Pass RF, Duliege AM, Boppana S et al. A subunit Cytomegalovirus vaccine based on recombinant envelope glycoprotein B and a new adjuvant. J. Infect. Dis. 180(4), 970-975 (1999).

-. First clinical trial of gB/MF59 displaying safety and immunogenicity.

65 Frey SE, Harrison C, Pass RF et al. Effects of antigen dose and immunization regimens on antibody responses to a Cytomegalovirus glycoprotein B subunit vaccine. J. Infect. Dis. 180(5), 1700-1703 (1999).

66 Mitchell DK, Holmes SJ, Burke RL, Duliege AM, Adler SP. Immunogenicity of a recombinant Human cytomegalovirus $\mathrm{gB}$ vaccine in seronegative toddlers. Pediatr. Infect. Dis. J. 21(2), 133-138 (2002).

67 Pass RF, Zhang C, Evans A et al. Vaccine prevention of maternal Cytomegalovirus infection. N. Engl. J. Med. 360(12), 1191-1199 (2009).

-• Phase II clinical trial of gB/MF59 displaying efficacy in at-risk population.

68 Griffiths PD, Stanton A, Mccarrell E et al. Cytomegalovirus glycoprotein-B vaccine with
MF59 adjuvant in transplant recipients: a Phase 2 randomised placebo-controlled trial. Lancet 377(9773), 1256-1263 (2011).

- Phase II clinical trial of gB/MF59 displaying efficacy in at-risk population.

69 Bernstein DI, Munoz FM, Callahan ST et al. Safety and efficacy of a Cytomegalovirus glycoprotein $\mathrm{B}(\mathrm{gB})$ vaccine in adolescent girls: a randomized clinical trial. Vaccine 34(3), 313-319 (2016).

70 Sabbaj S, Pass RF, Goepfert PA, Pichon S. Glycoprotein B vaccine is capable of boosting both antibody and CD4 T-cell responses to Cytomegalovirus in chronically infected women. J. Infect. Dis. 203(11), 1534-1541 (2011).

71 Axelsson F, Adler SP, Lamarre A, Ohlin M. Humoral immunity targeting site I of antigenic domain 2 of glycoprotein B upon immunization with different Cytomegalovirus candidate vaccines. Vaccine 26(1), 41-46 (2007).

72 Ohlin M. A new look at a poorly immunogenic neutralization epitope on Cytomegalovirus glycoprotein B. Is there cause for antigen redesign? Mol. Immunol. 60 (2), 95-102 (2014).

73 Williams GR, Kubajewska I, Glanville N, Johnston SL, Mclean GR. The potential for a protective vaccine for rhinovirus infections. Expert Rev. Vaccines 15(5), 569-571 (2016).

74 Gibson L, Piccinini G, Lilleri D et al. Human cytomegalovirus proteins pp 65 and immediate early protein 1 are common targets for $\mathrm{CD}^{+}$ $\mathrm{T}$ cell responses in children with congenital or postnatal Human cytomegalovirus infection. J. Immunol. 172(4), 2256-2264 (2004).

75 Wills MR, Carmichael AJ, Mynard K et al. The human cytotoxic T-lymphocyte (CTL) response to Cytomegalovirus is dominated by structural protein pp65: frequency, specificity, and T-cell receptor usage of pp65-specific CTL. J. Virol. 70 (11), 7569-7579 (1996).

76 Vaz-Santiago J, Lule J, Rohrlich P et al. Ex vivo stimulation and expansion of both CD4 $\left(^{+}\right)$and $\mathrm{CD} 8\left(^{+}\right) \mathrm{T}$ cells from peripheral blood mononuclear cells of Human cytomegalovirus-seropositive blood donors by using a soluble recombinant chimeric protein, IE1-pp65. J. Virol. 75(17), 7840-7847 (2001).

77 Gil A, Shen S, Coley S et al. DNA vaccine prime followed by boost with live attenuated virus significantly improves antigen-specific T cell responses against Human cytomegalovirus. Hum. Vaccin. Immunother. 9(10), 2120-2132 (2013).

- A preclinical vaccination study demonstrating that DNA vaccine priming to known T-cell antigens can increase T-cell responses following live HCMV challenge.

78 Wussow F, Chiuppesi F, Martinez J et al. Human cytomegalovirus vaccine based on the envelope gH/gL pentamer complex. PLoS Pathog. 10(11), e1004524 (2014).

- A preclinical vaccination study of the HCMV pentamer that demonstrates potent induction of neutralizing antibodies. 